Vol. 5, No. 1, 2020

\title{
COMPARISON OF THE METHODS OF SURFACE RUNOFF MODELLING FROM THE URBANIZED SUBCATCHMENTS FOR ESTIMATION OF PEAK LOADS ON THE ENVIRONMENT
}

\author{
Ihor Mysak, Volodymyr Zhuk, Kateryna Petrushka \\ Lviv Polytechnic National University, \\ 12, S. Bandery Str., Lviv, 79013, Ukraine \\ ihor_mysak@yahoo.com,zhuk_vm@ukr.net
}

https://doi.org/10.23939/ep2020.01.001

Received: 02.12.2019

(C) Mysak I., Zhuk V., Petrushka K., 2020

\begin{abstract}
Stormwater hydrographs from the typical urban impervious subcatchments are analyzed theoretically using the nonlinear reservoir method and the sector method. The peak flow rates of hydrographs from the impervious rectangular subcatchments are 0.774 times less using the nonlinear reservoir method comparing the sector method for all investigated input parameters.
\end{abstract}

Key words: surface runoff; impervious subcatchment; nonlinear reservoir method; sector method; stormwater hydrograph.

\section{Introduction}

The ecological status of surface water bodies still strongly depends on the intensity of human activity [1]. Anthropogenic influence is noticeable even in areas far from large cities where population density is relatively low [2]. One of the main sources of contamination is surface runoff. As usual, most environmentally hazardous runoff is obtained from the highly urbanized impervious subcatchments, e.g. the highway facilities [3].

Drastic turbulences of the rainfall parameters due to the global climate changes along with the intensive urbanization of the catchments lead to an increase in the requirements for the reliability of the municipal stormwater drainage systems. The model of the surface runoff from the urbanized areas is a complex multifactor problem. Strong impact on the stormwater hydrographs from the urbanized catchments have the statistical climatic parameters of rainfall events, the topography and the geodetic parameters of the subcatchment (form and dimensions in the plan, longitudinal and transverse slopes of the surface, etc.), hydraulic and hydrological parameters of the subcatchment (roughness coefficient, infiltration rate of the soil, etc.), as well as local features of the drainage schemes of the stormwater routing through the open and underground facilities Such a high level of complexity causes the necessity of using computer models for obtaining the rainfall-runoff function in any particular case. Today, about two dozen software complexes are used in the world to model the quantitative and qualitative parameters of the stormwater runoff $[4,5,6$, $7,8]$. There are about ten principally different approaches, allowing to estimate the surface runoff hydrographs: from empirical methods of rational formula and individual hydrographs, quasi-physical method of nonlinear reservoir to hydraulically based methods of kinematic and diffusion waves $[9,10]$, method of directed graphs [11] and the method of fuzzy logic [12].

Last decades, worldwide usage in urban stormwater modelling obtained the SWMM platform developed by the US Environmental Protection Agency (US EPA) [4]. SWMM was first presented in 1969-1971, and since then has undergone many stages of the upgrade. The latest version of SWMM 5/5.1.011 has a completely open source that can be downloaded from the EPA website.

In the SWMM software, the surface runoff hydrographs are modelled only by the method of a nonlinear reservoir. The main deficiency of the nonlinear method from the hydraulic point of view is the assumption concerning the constant values of the surface flow depth and velocity in all the points of the subcatchment, whenever it is obvious that the flow rate, depth, and the average velocity of the surface flow increase along with the flow. To improve the hydraulic method of calculating the surface runoff from urbanized subcatchments, a modified kinematic-wave method was justified in paper [10], and a new sector method was substantiated and tested in [13]. Besides, the physicallybased governing equation sector method handles 
subcatchments of arbitrary geometric shape: from the simplest linear or radial to any polygonal shape.

The purpose of this paper is to compare the hydrographs from the typical square fully impervious catchments obtained by the sector method and using the nonlinear reservoir method.

Objectives of the study: to analyze the assumptions and mathematical models applied in the sector method and the nonlinear reservoir method; to consider technical features of numerical implementation of both methods; to perform a series of numerical simulations for comparing the dimensional and non-dimensional stormwater hydrographs from typical square fully impervious catchments using the sector method and the nonlinear reservoir method.

\section{Materials and methods}

The theoretical and numerical methods of the investigation of the surface runoff hydrographs are used in this research. Stormwater hydrographs for the nonlinear reservoir method were obtained analytically by solving the Chini's differential equation, numerically using the finite element method, and the convergence of the results was checked using the SWMM program, version 5/5.1.011. Stormwater hydrographs for the sector method were calculated numerically by the finite element method.

\section{Results and Discussion}

\subsection{Rainfall - runoff modelling using the nonlinear reservoir method}

The first stage of the computerized hydraulic calculation of the stormwater drainage system is the modelling of the surface runoff hydrographs from the individual subcatchments. In the case of the most detailed modelling, each subcatchment should be a part of an urbanized catchment with a single stormwater inlet structure.

The essence of the method is the fact that the subcatchment is represented in the rectangle form of the same area with an equivalent width Beq, which is defined as the ratio of the subcatchment area and the length of the path of the surface concentration of Rcon. The discharge of surface runoff in the nonlinear reservoir method is determined by the Chezy equation for the uniform

$$
\begin{aligned}
& A_{1}=(1+\sqrt{5}) \ln \left[k^{2 / 5} h^{2 / 3}-(\sqrt{5}-1) k^{1 / 5} q_{e x}^{1 / 5} h^{1 / 3} / 2+q_{e x}^{2 / 5}\right]-(\sqrt{5}-1) \ln \left[k^{2 / 5} h^{2 / 3}+(\sqrt{5}+1) k^{1 / 5} q_{e x}^{1 / 5} h^{1 / 3} / 2+q_{e x}^{2 / 5}\right]- \\
& -4 \ln \left(q_{e x}^{1 / 5}-k^{1 / 5} h^{1 / 3}\right)-2(10-2 \sqrt{5})^{1 / 2} \operatorname{arctg}\left[\frac{4 k^{1 / 5} h^{1 / 3}-(\sqrt{5}-1) q_{e x}^{1 / 5}}{(10+2 \sqrt{5})^{1 / 2} q_{e x}^{1 / 5}}\right]+ \\
& +2(10+2 \sqrt{5})^{1 / 2} \operatorname{arctg}\left[\frac{4 k^{1 / 5} h^{1 / 3}+(\sqrt{5}+1) q_{e x}^{1 / 5}}{(10-2 \sqrt{5})^{1 / 2} q_{e x}^{1 / 5}}\right]
\end{aligned}
$$

Constant $C_{l}$ for each combination of the $q_{e x}$ and $k$ values should be find numerically from the condition $h(0)=0$. that the depth and, accordingly, the flow velocity are the same at all the points of the subcatchment $[4,5]$.

The flow rate using Chezy equation for a uniform flow in an open channel of a rectangular cross-section

$$
Q_{c o n}=\frac{B_{e q} R_{h}^{5 / 3} i_{c o n}^{1 / 2}}{n_{1}},
$$

where $B_{e q}$ is the equivalent width of the subcatchment, which is defined as the ratio of the subcatchment's area and the radius of the surface runoff concentration $R_{c o n} ; R_{h}$ is the hydraulic radius of the surface flow, which for shallow surface flows is equal to the depth $h ; i_{\text {con }}$ is the longitudinal slope of the subcatchment's area to the stormwater inlet; $n_{l}$ is the Manning's roughness coefficient.

The differential equation of the material balance of the volume of surface runoff $W(t)$ :

$$
\frac{d W}{d t}=F q_{e x}-Q_{c o n},
$$

where $F$ is the subcatchment area; $q_{e x}$ is the excessive intensity of the stormwater event, defined as the difference between the rainfall intensity and the total intensity of infiltration and evaporation.

Thus, the depth or the layer of surface runoff $h(t)$ should be find from the nonlinear differential equation:

$$
\frac{d h}{d t}=q_{e x}-\frac{B_{e f} i_{c o n}^{1 / 2}}{F n_{1}} h^{5 / 3} .
$$

Main governing equation of the nonlinear method (3) is a first-order nonlinear ordinary differential equation or Chini's equation. It is possible only indirect analytical solution of the eq. (3) as a dependence of time $t$ from the depth $h$, instead the function $h(t)$, necessary to calculate hydrograph:

$$
t=\frac{3 A_{1}}{20 q_{e x}^{2 / 5} k^{3 / 5}}+C_{1},
$$

where $k$ is the coefficient, depending only on the catchment's surface parameters:

$$
k=\frac{B_{e f} i_{c o n}^{1 / 2}}{F n_{1}} .
$$

Value $A_{l}$ in the solution (4) is a complex function of

After the rainfall stops governing equation (3) of the non-linear method is simplified to 


$$
\frac{d h}{d t}=-\frac{B_{e f} i_{c o n}^{1 / 2}}{F n_{1}} h^{5 / 3}=-k t .
$$

The solution of (7) is

$$
h(t)=\left[h_{\max }^{-2 / 3}+2 k\left(t-t_{r}\right) / 3\right]^{-3 / 2},
$$

where $h_{\max }$ is the maximal depth in the moment of time $t=t_{r}$, where $t_{r}-$ critical rainfall duration.

Hence the value $h_{\max }$ should be found from the equations (4)-(6) at the moment of time $t=t_{r}$.

An important deficiency of the nonlinear reservoir method is the absence of the recommendation concerning the determination of the critical rainfall duration and, hence, the rainfall intensity. The practical realization of the nonlinear reservoir method in the SWMM environment consists in the sequential modelling of the runoff hydrographs from stormwater events with different duration and intensity, and in the subsequent comparison of the obtained hydrographs and the empirical definition with a certain approximation due to the size of the time step, the parameters of the critical rainfall, causing the maximum flow rate in the control section of the stormwater drainage system.

\subsection{Sector method of the stormwater hydrographs routing}

In the paper [13] a new hydraulically based sector method was introduced by the specialists of Lviv Polytechnic National University (LPNU). This method is a modification of the kinematic wave method and it can be used for calculating the surface runoff hydrographs from drainage basins of arbitrary configuration. The main parameters of the sector method are variable depths and velocities of the surface runoff. Using the sector method, the time of surface concentration:

$$
t_{r}=\left[\frac{1.41\left(R_{c o n} \mathrm{n}_{1}\right)^{0.6}}{\left(1200^{n} \Psi_{\text {mid }} q_{20}\right)^{0.4} i_{c o n}^{0.3}}\right]^{\frac{1}{1-0.4 n}},
$$

where $R_{\text {con }}$ is the concentration radius of the subcatchment, $\mathrm{m}$; $\psi_{\text {mid }}$ is the runoff coefficient; $q_{20}$ - rainfall intensity for demanded return period $P, \mathrm{~m} / \mathrm{s} ; n-$ power index in the intensity -duration formula

$$
q_{r}=A / t_{r}^{n},
$$

where $q_{r}$ is the intensity of the design rainfall of the duration $t_{r} ; A$ is the dimensionless parameter

$$
A=q_{20} 20^{n}\left(1+\frac{\lg P}{\lg m_{r}}\right)^{\gamma},
$$

where $m_{r}$ is the average annual number of rainfall events; $\gamma$ is the exponent; both depend from the climate conditions.

The idea of the sector method is that the subcatchment of an arbitrary configuration can be divided into a large number of narrow sectors with a vertex at the location of the stormwater inlet. Each sector with a high accuracy can be considered as a theoretical radial subcatchment. According to the method described in [13], elementary hydrographs are generated for each sector, and then, using the superposition principle, the total hydrograph from the whole subcatchment is determined.

\subsection{Tested subcatchments}

In this study, we investigated the square subcatchments with different values of linear sizes $L=B$ in the range of 10-50 m. We tested the square configuration due to a reason that stormwater hydrographs from the square subcatchment are the maximum possible among all rectangular subcatchments of the same area [13], and rectangular subcatchments are the most common in practice, which allows to obtain more outlined results. The longitudinal slope of the subcatchment's surface $i_{c o n}$ is assumed to be uniform in all its points and directed towards the stormwater inlet $\mathrm{O}$ (Fig. 1).

The radius of the $i$-th sector is defined as a function of the polar angle $\varphi_{i}$ :

$$
\begin{array}{ll}
-0<\varphi_{\mathrm{i}} \leq \pi / 4: & R_{i}=L / \cos \left(\phi_{i}\right) ; \\
-\pi / 4<\varphi_{\mathrm{i}} \leq \pi / 2: & R_{i}=L / \sin \left(\phi_{i}\right) .
\end{array}
$$

The subcatchment was divided into 180 elementary sectors, each with the same central angle $\Delta \varphi=0.5^{\circ}$.

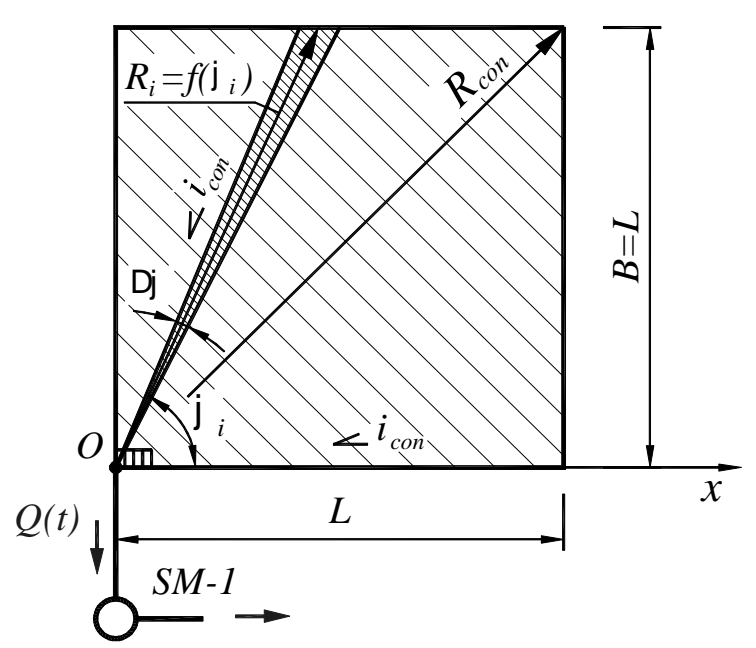

Fig. 1. Scheme of the tested square subcatchment: $R_{i}$, is the radius of concentration and $\varphi_{\mathrm{i}}$

is the polar angle of $i$-th sector; $O$ is the stormwater inlet location; SM-1 is the sewer manhole \#1

For each elementary sector, its characteristic concentration time was determined:

$$
t_{r, i}=\frac{1.41\left(R_{i} n_{1}\right)^{0.6}}{\left(\Psi_{\text {mid }} q_{r}\right)^{0.4} i_{c o n}^{0.3}},
$$

where rainfall intensity $q_{r}$ is the same for all the sectors. 
In this study, a surface runoff with completely impervious subcatchments with a zero depth of the initial detention was considered, thus, it was assumed that runoff coefficient $\psi_{\text {mid }}=1$ in all points of the subcatchment at any time. So, a partial hydrograph from the $i$-th elementary sector was described by formulas for a theoretical hydrograph from analogical radial subcatchment:

$$
\begin{gathered}
-0<t \leq t_{r . i}: \quad Q_{i}(t)=Q_{r . i}\left(t / t_{r . i}\right)^{10 / 3} \\
-t_{r . i}<t \leq t_{r}: \quad Q_{i}(t)=Q_{r . i} \\
-t_{r}<t \leq\left(t_{r}+t_{r . i}\right): Q_{i}(t)=Q_{r . i}\left[1-\left(t-t_{r}\right) / t_{r . i}\right]^{10 / 3} \\
-t>\left(t_{r}+t_{r . i}\right): \quad Q_{i}(t)=0
\end{gathered}
$$

The total flow rate of the surface runoff from a subcatchment at point $O$ at any time $t$ was defined as the sum of the partial flow rates $Q_{i}$ at this moment. The time step $\Delta t_{i}$ was assumed equal

$$
\Delta t_{i}=t_{\text {con }} / 200 \text {, }
$$

where $t_{c o n}-$ is the time of surface concentration from the entire subcatchment, which is determined by equation (9) and corresponds to the full radius of concentration $R_{c o n}$; for square subcatchments with stormwater inlet located in its vertex $R_{c o n}=\sqrt{2} L$.

\subsection{Stormwater hydrographs, modelled by the sector method and by the nonlinear method}

The results of numerical simulation of surface runoff hydrographs from square subcatchments with dimensions of $50 \times 50 \mathrm{~m}$ for climatic conditions in Lviv city at a period of $P=1$ year are shown in Fig. 2. In all cases, the longitudinal slope of the subcatchment towards the stormwater inlet was assumed to be a constant $i_{\text {con }}=0.01$, since such a slope is most common in elevation planning of sites with impervious area. Hydrographs in Fig. 2 obtained for different values of the roughness coefficient $n_{1}$ in the range of $0.012-0.025$, with odd-numbered hydrographs obtained using the sector method, and the pair hydrographs - using the non-linear reservoir method.

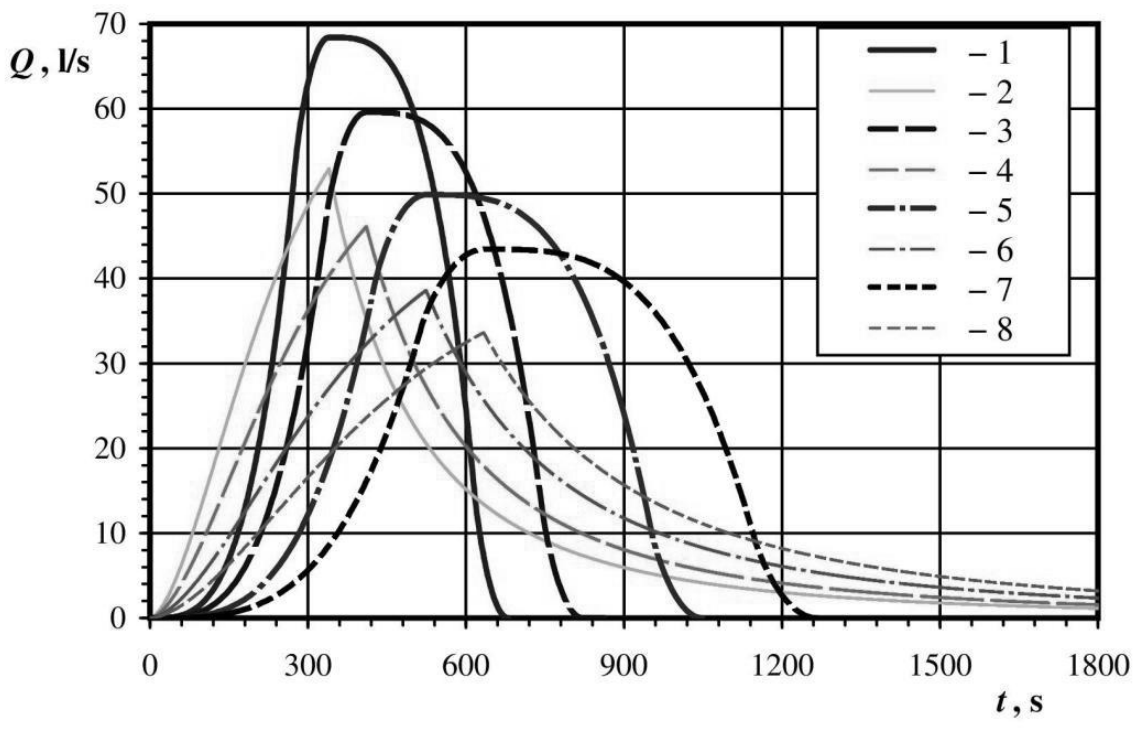

Fig. 2. Surface runoff hydrographs from impervious subcatchments $50 \times 50 \mathrm{~m}$ at different roughness coefficient $n_{1}$ of the surface: $1,2-0.012 ; 3,4-0.015 ; 5,6-0.02$; $7,8-0.025 ; 1,3,5,7-$ using the sector method;

$2,4,6,8-$ by nonlinear reservoir method $\left(q_{20}=109 \mathrm{l} /(\mathrm{s} \times \mathrm{ha}) ; P=1\right.$ year; $\left.n=0.73 ; \psi_{\mathrm{mid}}=1 ; i_{c o n}=0.01\right)$

Hydrographs obtained by the sector method are systematically different from similar hydrographs derived by the nonlinear reservoir method: they are characterized by a more rapid increase of the flow rate in the second half of the first stage of the hydrograph, significantly higher maximum flow rates, and sudden decreasing of the flow rate after the rainfall event. Hydrographs obtained by the sector method are more problematic in terms of their impact on the drainage network and the potential of flooding of the urban area.

Decreasing the roughness of subcatchment's surface directly leads to decreasing of the surface concentration time, an increasing of the peak flow rate, and to the concentration of most of the runoff volume in a shorter time interval. The dependences of the maximum runoff flow on the roughness factor for the test pools of $50 \times 50 \mathrm{~m}$ 
are shown in Fig. 3. The constant value of the ratio of maximum flow rates by the nonlinear reservoir method and by the sector method is obtained:

$$
Q_{r . n-l} / Q_{r . s}=0.774 \text {. }
$$

The constant value of the maximum flow rates ratio $Q_{r . n-l} / Q_{r . s}$ is also obtained for all other investigated input parameters, including a baseline $20 \mathrm{~min}$ rainfall intensity $q_{20 . P}$ and an exponent $n$ in the intensity duration dependency (10).

Maximum flow rates are compared when using the nonlinear reservoir method and the sector method for rectangular subcatchments of different configuration. Despite the unsimilarity of the stormwater hydrographs by the parameter $L / B$, the peak flow rate ratio also does not depend even on this input parameter (Fig. 4, Table 1).

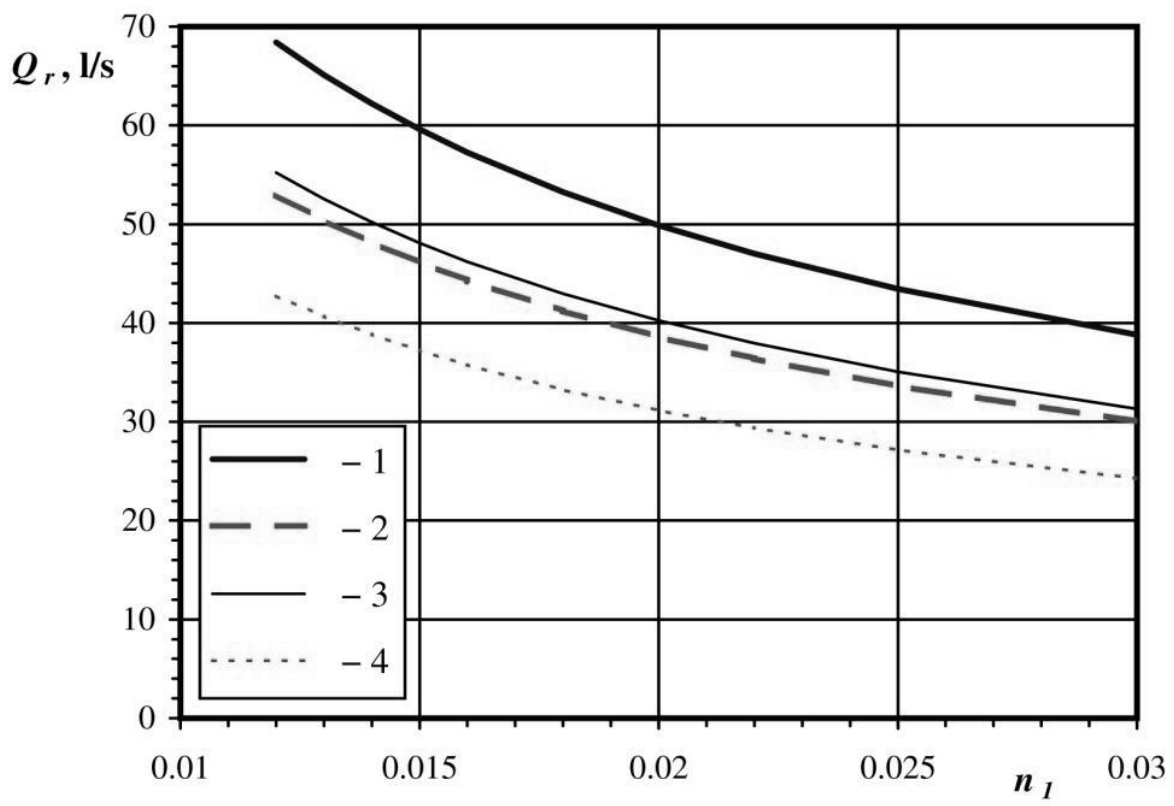

Fig. 3. Stormwater peak discharge as function of the roughness coefficient $n_{l}$ for different slopes $i_{c o n}$ : $1,2-0.01 ; 3,4-0.005 ; 1,3$ - using the sector method; $2,4-$ by nonlinear reservoir method $\left(q_{20}=1091 /(\mathrm{s} \times\right.$ ha $) ; P=1$ year; $\left.n=0.73 ; F=2500 \mathrm{~m}^{2} ; L / B=1 ; \psi_{\text {mid }}=1\right)$

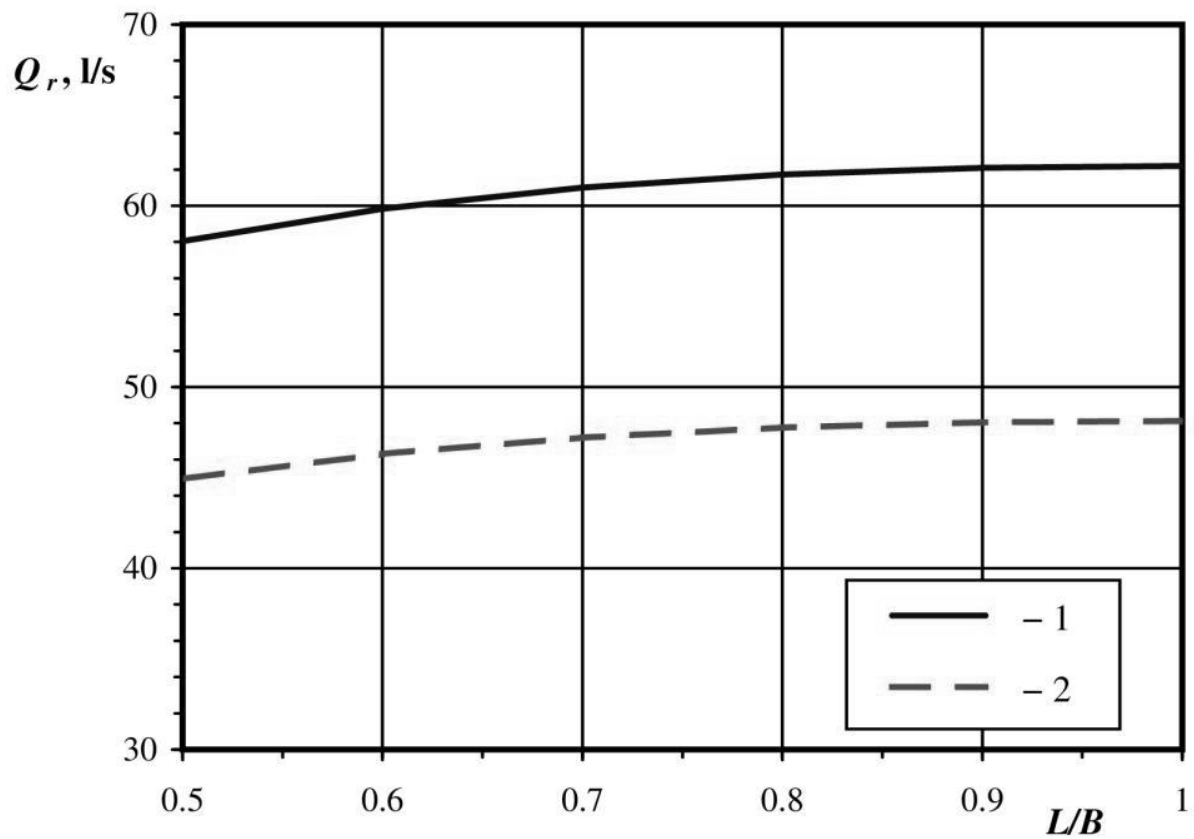

Fig. 4. Stormwater peak discharge as function of the catchment's configuration $L / B$ : 1 - using the sector method; 2 - by nonlinear reservoir method $\left(q_{20}=109 \mathrm{l} /(\mathrm{s} \times \mathrm{ha}) ; P=1\right.$ year; $\left.n=0.73 ; n_{l}=0.014 ; i_{c o n}=0.01 ; F=2500 \mathrm{~m}^{2} ; \psi_{\text {mid }}=1\right)$ 
Stormwater peak flow rates obtained by the nonlinear reservoir method and by the sector method as a function of the subcatchment dimensions ratio $L / B$

\begin{tabular}{|c|c|c|c|c|c|c|}
\hline$L / B$ & 1 & 0.9 & 0.8 & 0.7 & 0.6 & 0.5 \\
\hline$Q_{r . n-l}, 1 / \mathrm{s}$ & 48.13 & 48.05 & 47.77 & 47.21 & 46.30 & 44.92 \\
\hline$Q_{r . s,}, / \mathrm{s}$ & 62.19 & 62.08 & 61.72 & 61.00 & 59.83 & 58.04 \\
\hline$Q_{r . n-l} / Q_{r . s}$ & 0.77395 & 0.77395 & 0.77393 & 0.77395 & 0.77395 & 0.77395 \\
\hline
\end{tabular}

\section{Conclusions}

The advantages and disadvantages of the nonlinear reservoir method, which is used to model the stormwater hydrographs from urban drainage subcatchments, are analyzed. The general theoretical solution of the governing differential equation of the nonlinear reservoir method in implicit form is obtained as a solution of the of Chini's differential equation.

Comparison of the stormwater runoff hydrographs obtained by numerical simulation and using two different methods: nonlinear reservoir method, widely used in the practice, particular in SWMM program, and the sector method developed in LPNU (Ukraine). Simple and explicit schemes for the numerical implementation of both methods are developed. The inflow hydrographs from rectangular fully impervious subcatchments with ratio $L / B=1$ are obtained and analyzed for different values of the surface roughness coefficient in the range from 0.012 to 0.03 .

The application of the non-linear reservoir method with all identical input parameters causes peak runoff flow rate of $22.6 \%$ less comparing the sector method, which can lead to the underestimation of stormwater discharge in the actual modelling of the stormwater runoff at the urban areas. The constant value of the ratio of peak flow rates, modelled using the nonlinear reservoir method and the sector method $Q_{r . n-l} / Q_{r . s}=0.774$ is obtained for all investigated input parameters, including baseline $20 \mathrm{~min}$ rainfall intensity $q_{20 . P}$, exponent $n$ in the intensity - duration dependency, and the subcatchment's dimensions ratio $L / B$.

\section{References}

[1] European waters. Assessment of status and pressures 2018. EEA Report No7/2018. European Envir. Agency. 2018, 85 .

[2] Masikevych A., Malovanyy M., Yaremchuk V., Kolotylo M., Masikevych Y.: J. Envir. Probl., 2018, 3(4), 265.

[3] Iurchenko V., Melnikova O., Mikhalevich N., Borzenko O.: J. Envir. Probl., 2019, 4 (2), 74. https://doi.org/10.23939/ep2019.02.074

[4] James W., Rossman L.: Water systems models. User's guide to SWMM 5, 13th ed. CHI Press Publication, Ontario, Canada. 2010, 905.

[5] Tkachuk S. G. and Zhuk V. M.: Reghuljuvannja doshchovogho stoku $\mathrm{v}$ systemakh vodovidvedennja: monoghrafija. Vydavnyctvo Lvivskoji politekhniky, Lviv 2012. (in Ukrainian)

[6] Borah D. K.: Hydrol. Proces., 2011, 25, 3472.

[7] Hromadka T. V.: Environ.Software, 1990, 5 (2), 82.

[8] Moradkhani H.: General review of rainfall-runoff modeling: model calibration, data assimilation, and uncertainty analysis [in:] Sorooshian S., Hsu K. L., Coppola E., Tomassetti B., Verdecchia M., Visconti G. (Ed.), Hydrological Modelling and the Water Cycle. Water Science and Technology Library. Springer Science + Business Media B.V. 2009, 63, 1-24.

[9] Xiong Y., Melching C.S.: J. Hydrol. Eng., 2005, 10(1), 39.

[10] Zhuk V. M.: Visn. Nats. Univ. Lviv Polytechnic "Theory and Practice of Construction", 2007, 602, 61. (in Ukrainian)

[11] Berko A., Zhuk V., Sereda I.: J. Envir. Probl., 2017, $2(2), 97$.

[12] Wang K. H., Altunkaynak A.: J. Hydrol. Eng. 2012, 17(2), 281.

[13] Zhuk V. M., Matlai I. I.: Probl. of Water Supply, Sewerage and Hydraulics, 2012, 19, 31. (in Ukrainian) 